\title{
Modelling climate impacts on crop yields in Belgium
}

\author{
A. Gobin* \\ Environmental Modelling Unit, Flemish Institute for Technological Research, Boeretang 200, 2400 Mol, Belgium
}

\begin{abstract}
In the last 2 decades, Belgium has experienced more monthly extremes than in any other decade since observations began in 1833. During the past $60 \mathrm{yr}$, yields have increased, on average, by $0.1 \mathrm{t} \mathrm{ha}^{-1} \mathrm{yr}^{-1}$ for winter cereals, $0.4 \mathrm{t} \mathrm{ha}^{-1} \mathrm{yr}^{-1}$ for potato and $0.6 \mathrm{t} \mathrm{ha}^{-1} \mathrm{yr}^{-1}$ for sugar beet. A total of 60 to $74 \%$ of the variability in yields between 1960 and 2008 was explained by meteorological variables. Multivariate analysis showed significant statistical relationships between yield and vapourpressure deficit, temperature and growing season length, and water logging and drought. These variables were therefore included in a new regional dynamic crop model (REGCROP) developed to assess climate impacts on regional arable crop production. Nash-Sutcliffe model efficiencies were between 0.68 and 0.84 between simulated and observed national yields for the period 1960-2008. REGCROP was subsequently run for 3 climate change scenarios and 3 typical Belgian soils (clay, loam and loamy sand) and climate impacts were compared with historical weather impacts (1960-1989). Higher temperatures increase crop development and shorten the growing season. Strong projected changes in seasonality affect cumulative drainage for both winter and summer crops and result in a drier water balance regime with climate change. Average yield losses of 12 to $27 \%$ were simulated for sugar beet and 23 to $44 \%$ for potatoes owing to drought and heat stress. Projected losses for winter cereals are 5 to $12 \%$, mainly owing to waterlogging, whereas yield increases up to 6 or $7 \%$ are projected as a result of temperature increases and favourable vapour-pressure deficits.
\end{abstract}

KEY WORDS: Arable crop yield - Climate change impact - Regional dynamic crop model . Time series · Multivariate analysis

\section{INTRODUCTION}

During the past decades, climate change has had a marked influence on European agriculture (Orlandini et al. 2008, Reidsma et al. 2009). The impacts of the 2003 heat wave in Europe, with temperatures up to $6^{\circ} \mathrm{C}$ above long-term means and precipitation deficits up to $300 \mathrm{~mm}$, resulted in an estimated loss of $€ 13$ billion for the European agricultural sector (Ciais et al. 2005). Global coupled climate model results show that future heat waves in Europe will become more intense, more frequent and longer lasting in the 21st century (Meehl \& Tebaldi 2004). With climate defined as the average weather type during a period of a minimum of $30 \mathrm{yr}$, effects are on a temporal scale that are not accounted for in agricultural decision making. Consequently, the annual activities of farmers might not track the speed of climate change (Menzel et al. 2006a).

Experimental observation of physiological plant responses to meteorological variables has resulted in the development of a wide range of models applied at the plant, plot or field scale, such as CropSyst (Stockle et al. 2003), Daisy (Abrahamsen and Hansen, 2000), wheat simulation models (Porter et al. 1993), DSSAT (J. W. Jones et al. 2003) and STICS (Brisson et al. 2003). Crop models in conjunction with regional climate models enable the assessment of climate impacts on regional agriculture (Jacob et al. 2007). When employed in climate impact studies, inter-model comparisons demonstrate that uncertainties and sources of variation in projected climate impacts on agriculture depend not only on the emission scenarios and climate models, but also on the crop models used (Olesen et al. 2007). 
Crops often respond nonlinearly to changes in their growing conditions and have threshold responses; this greatly increases the importance of climatic variability and frequency of extreme events for yield, yield stability and quality (Porter \& Semenov 2005). Many of the crop models were originally developed to predict crop responses to local weather conditions and might not capture some of the current findings on feedback mechanisms and threshold effects under new climatic conditions or extreme weather events, nor might they be suited to applications at the regional scale.

With climate change, increased air temperature and $\mathrm{CO}_{2}$ enrichment are projected to significantly affect crop phenology, reduce stomatal conductance and transpiration, improve water-use efficiency and stimulate higher rates of photosynthesis (Drake et al. 1997, Chmielewski et al. 2004, Menzel et al. 2006b, Kattge \& Knorr 2007). Results from the Free Air Carbon Enrichment (FACE) experiments cast doubts on whether $\mathrm{CO}_{2}$ fertilisation will fully offset yield losses resulting from decreased soil moisture or increased heat stress under climate change (Ewert et al. 2002, Kimball et al. 2002, Long et al. 2006). The discrepancy between modelling efforts and experiments is possibly related to the fact that the majority of crop models predict yield with a non-limiting supply of water and near-optimum temperature for crop growth. Current impacts of climate change or extreme weather events on agricultural production enable further exploration of upper or lower model boundary conditions and result in improved models suited to simulate climate impacts.

Seasonal patterns in agro-meteorological variables have a major impact on regional crop production (Wheeler et al. 2000, Challinor et al. 2003). All of the processes involved in agricultural production take place at different spatial, temporal and organisational scales. Reconciliation across this range of scales requires explicit integration over temporal distributions of meteorological, soil, crop and agro-economic data. The physical basis for regional crop modelling relies on a quantified relationship between weather and yield data at particular temporal scales. Regional crop models have been developed to a limited extent, e.g. to investigate the effects of climate change on grain yields in China (Mo et al. 2009) and groundnut yields in India (Challinor et al. 2004). The focus of the present study is the development of a regional crop model that can be used to assess climate impacts on regional arable crop production.

Based on a long-term temperature analysis for Ukkel, the Belgian Royal Meteorological Institute (RMI 2009) distinguished a first period (1910-1987) with an average mean temperature of $9.7^{\circ} \mathrm{C}$ followed by an abrupt rise in 1988 resulting in a second period with an average mean temperature of $10.9^{\circ} \mathrm{C}$. The impacts of climate change on 4 arable crops in Belgium were assessed using time series and multivariate analysis of meteorological and yield observations, a newly developed regional dynamic crop model (REGCROP), regional IPCC climate scenarios and economic evaluation indicators. Model results are presented for historical observations and 3 climate-change scenarios on 3 typical Belgian soils. Together, the 4 crops selected represent $€ 843$ million or $80 \%$ of the 2008 total arable crop production in Belgium. According to 2008 Belgian agricultural census data, winter wheat Triticum aestivum L. $\left(2086 \mathrm{~km}^{2}\right)$ and winter barley Hordeum vulgare L. $\left(488 \mathrm{~km}^{2}\right)$ represent $71 \%$ of the total cereal production area. Potato Solanum tuberosum L. $\left(639 \mathrm{~km}^{2}\right)$ and sugarbeet Beta vulgaris L. $\left(643 \mathrm{~km}^{2}\right)$ each represent $37 \%$ of the industrial crop production area.

\section{METHODS}

\subsection{Weather and yield data analysis}

Historical weather records for the period 1947-2008 from the Belgian Royal Meteorological Institute (RMI) were used to calculate seasonal, monthly and 10-daily rainfall, minimum and maximum air temperature, solar radiation, wind speed, dewpoint temperature and relative humidity. Vapour pressure deficit (VPD) and potential evapotranspiration (PET) were calculated using the FAO Penman-Monteith equation (Allen et al. 1998):

$$
\begin{gathered}
\mathrm{VPD}=\frac{e^{0}(T \min )+e^{0}(T \max )}{2}-e^{0}(T \text { dew }) \\
\text { with } \\
e^{0}(T)=0.6108 \exp \left(\frac{17.27 \times T}{T+273.3}\right)
\end{gathered}
$$

where $e^{0}(T)$ is saturation vapour pressure (in $\mathrm{kPa}$ ) at the air temperature $T\left(\mathrm{in}^{\circ} \mathrm{C}\right), T \mathrm{~min}$ is minimum temperature, Tmax is maximum temperature, $T$ dew is temperature at dewpoint. Extreme values were defined as the days with non-zero-value 10th and 90th percentiles for evapotranspiration and rainfall, and days with mean temperatures above $30^{\circ} \mathrm{C}$. Days with VPD between 0.45 and 1.25 were used to identify healthy air-moisture conditions for plant production; VPD values outside these boundaries were considered extreme.

A generic soil-moisture balance was developed to generate agri-meteorological variables that reflect soil-moisture conditions. The soil available water capacity was set to $200 \mathrm{~mm}$; the fraction of plant available water to 0.5 and the rooting depth to $1.5 \mathrm{~m}$. Daily actual evapotranspiration (AET) of the soil-plantatmosphere continuum was described as a dynamic 
function of rainfall (P) and PET, taking into account a daily $75 \%$ loss of storage capacity (ST). For rainfall events $<0.1 \mathrm{~mm}$ during the growing season, the ratio between actual and potential evapotranspiration was set at the average between 0.5 and the ratio:

$$
k_{t}=\frac{\mathrm{ST}_{t}}{\mathrm{PET}_{t}} \quad \text { with } \quad \mathrm{ST}_{t}=0.9 \times \mathrm{ST}_{t-1}+\mathrm{P}_{t}
$$

where $t$ is the time step (i.e. $1 \mathrm{~d}$ ).

The growing season was defined in accumulated thermal sums above the base temperature $0^{\circ} \mathrm{C}$. Vegetation growth was assumed between the days of the year when the accumulated thermal sum equals 100 and when the accumulated thermal sum for a period of $10 \mathrm{~d}$ is below 5, i.e. roughly from March until October. The soil-moisture balance operates as a single-layer bucket model that varies with the rooted soil layer. The rooting depth increases at constant rate, from $10 \mathrm{~cm}$ at

Table 1. Soil variables after Saxton \& Rawls (2006). Textures are based on USDA classifications

\begin{tabular}{|lrrrrrrr|}
\hline Texture & $\begin{array}{c}\text { Sand Clay } \\
(\%)\end{array}$ & \multicolumn{2}{c}{$\begin{array}{c}\text { Moisture content (vol \%) at } \\
\text { Wilting } \\
\text { point }\end{array}$} & $\begin{array}{c}K_{\text {sat }} \\
\text { capacity }\end{array}$ & $\begin{array}{c}\text { Bulk } \\
\left(\mathrm{mm} \mathrm{h}^{-1}\right)\end{array}$ & $\begin{array}{c}\text { density } \\
\left(\mathrm{g} \mathrm{cm}^{-3}\right)\end{array}$ \\
\hline Loamy sand & 82 & 6 & 5.7 & 12.1 & 45.7 & 91.3 & 1.44 \\
Silty loam & 8 & 13 & 10.0 & 33.0 & 48.9 & 13.9 & 1.35 \\
Loam & 30 & 25 & 16.4 & 31.9 & 47.2 & 9.7 & 1.40 \\
\hline
\end{tabular}

the beginning of the growing season to the maximum rooting depth at the middle of the growing season. Daily soil moisture ( $\theta_{t}$ Eq. 4$)$ is confined between field capacity $\left(\theta_{\mathrm{FC}}\right)$ and permanent wilting point $\left(\theta_{\mathrm{WP}}\right)$ (Table 1); losses such as runoff $(L)$ are assumed to be $10 \%$ of the total rainfall. Soil-moisture balance performance indicators include deficit with respect to plant available water, surplus with respect to field capacity, excess with respect to saturation and extreme values defined as the days exceeding non-zero-value 10th and 90th percentiles.

$$
\begin{gathered}
\mathrm{AET}_{t}=\frac{\left(k_{t}+k_{t}^{2}\right)}{\left(1+k_{t}+k_{t}^{2}\right)} \mathrm{PET}_{t} \quad \text { for } \mathrm{P}>0.1 \mathrm{~mm} \\
\theta_{t}=\theta_{t-1}+\left(\mathrm{P}_{t}-L_{t}-\mathrm{AET}_{t}\right) \times \Delta t
\end{gathered}
$$

All meteorological variables were integrated between average planting and harvesting dates for the 4 crops (Table 2) and $\Delta t$ equals $1 \mathrm{~d}$.

Agricultural census statistics on crop yields (Belgian Federal Government 2008) were detrended using linear regression. Detrending helped to define extreme yields, in terms of yield residuals below the 10th percentile and above the 90th percentile, which were used in further analysis of REGCROP model results. A multivariate correla-

\begin{tabular}{|c|c|c|c|c|c|c|}
\hline Crop parameter & Definition & Units & Winter wheat & Winter barley & Potato & Sugar beet \\
\hline$T_{\mathrm{b}}$ & Base temperature & ${ }^{\circ} \mathrm{C}$ & 4 & 4 & 7 & 6 \\
\hline$T_{\mathrm{o}}$ & Optimal temperature & ${ }^{\circ} \mathrm{C}$ & 25 & 25 & 30 & 30 \\
\hline$T_{\max }$ & Maximum temperature & ${ }^{\circ} \mathrm{C}$ & 35 & 35 & 35 & 35 \\
\hline Plant date & - & - & 15 Oct & 15 Oct & $15 \mathrm{Apr}$ & 20 Mar \\
\hline Harvest date $^{\mathrm{a}}$ & - & - & 01 Aug & $15 \mathrm{Jul}$ & 30 Sep & 21 Oct \\
\hline $\mathrm{PTU}^{\mathrm{b}}$ & Potential thermal units & ${ }^{\circ} \mathrm{C}$ & 1700 & 1450 & 1350 & 1800 \\
\hline a & & - & 3.055 & 3.055 & 3.055 & 2.08 \\
\hline$b$ & & - & 13.38 & 13.38 & 13.38 & 15.02 \\
\hline $\mathrm{LAI}_{\max }$ & Maximum leaf area index & - & 5.5 & 5.5 & 5.5 & 6 \\
\hline $\mathrm{HI}$ & Harvest index & - & 0.60 & 0.50 & 0.95 & 0.60 \\
\hline LUE & Light-use efficiency & $\mathrm{kg} \mathrm{ha}^{-1} \mathrm{MJ}^{-1} \mathrm{~m}^{2}$ & 30 & 28 & 30 & 33 \\
\hline Rooting depth & - & $\mathrm{m}$ & 1.60 & 1.60 & 0.50 & 0.95 \\
\hline Height & - & $\mathrm{m}$ & 0.85 & 0.80 & 0.70 & 0.4 \\
\hline$P$ factor & Depletion factor & - & 0.55 & 0.55 & 0.35 & 0.55 \\
\hline$K_{\mathrm{cb}}$ initial $^{\mathrm{c}}$ & Initial crop base factor & - & 0.17 & 0.17 & 0.15 & 0.15 \\
\hline$K_{\mathrm{cb}}$ mid & Mid-season crop base factor & - & 1.1 & 1.1 & 1.1 & 1.15 \\
\hline$K_{\mathrm{cb}}$ late & Late-season crop base factor & - & 0.3 & 0.3 & 0.35 & 0.5 \\
\hline$k_{s t}$ initial/vegetative $^{\mathrm{d}}$ & Sensitivity factors & start; end & $0.2 ; 0.2$ & $0.2 ; 0.2$ & $0.45 ; 0.45$ & $0.5 ; 0.8$ \\
\hline$k_{s t}$ reproductive ${ }^{\mathrm{d}}$ & & start; end & $0.2 ; 0.6$ & $0.2 ; 0.6$ & $0.8 ; 0.8$ & $0.8 ; 1.1$ \\
\hline$k_{s t}$ ripening/harvest $^{\mathrm{d}}$ & & start; end & $0.5 ; 0.2$ & $0.5 ; 0.2$ & $0.7 ; 0.2$ & $1.0 ; 0.7$ \\
\hline
\end{tabular}
tion analysis was carried out between

Table 2. Crop parameters for 4 Belgian crops. Data based on Blaes \& Defourny (2003), Allen et al. (1998) and Vanclooster et al. (1995) 
annual crop yields and different meteorological variables aggregated to the crop growth season, defined as the time between average planting and harvesting dates (Table 2). All meteorological variables and yields were compared between the RMI-defined climate periods (RMI 2009) using ANOVA. Linear regression equations were developed between crop yield and single meteorological variables with significant correlations. Non-linear multiple regression equations were developed using the 2 most significant and non-collinear meteorological variables. Multi-collinearity between the meteorological variables was revealed by means of principal components derived from the correlation matrix. In addition, a variance minimizing non-hierarchical (k-means) cluster analysis involving the selected meteorological variables was used to investigate the effect of climate period on the regression between the selected meteorological variables and yield.

\subsection{REGCROP model}

A regional dynamic crop model (REGCROP) was developed to assess climate impacts on regional crop production through the dynamic coupling of a water balance and a biomass production model run at a daily time step. The physical basis relies on quantified relationships between weather and yield at the regional scale. In thermodynamic terms, the radiation use efficiency of crop production is defined as the ratio between energy output (carbohydrates) to energy input (solar radiation) (Monteith \& Moss 1977). The amount of solar radiation intercepted depends on the seasonal distribution of leaf area, the development of which relies on ambient temperature and moisture supply in both soil and atmosphere. These biophysical concepts are related to the rate and duration of different crop development phases and are implemented in REGCROP.

Phenological crop development in REGCROP is based on thermal time using planting dates and cropspecific upper and lower threshold temperatures (Table 2), which form the boundaries of phenological activity. The threshold temperatures take into account the lag between air and soil temperatures, which is important for the early crop development stages. Crops are grown from planting dates until the accumulated thermal units (TU) equal the required potential thermal units (PTU). Depending on the crop and crop development stage, the thermal time is adjusted for vernalisation, dormancy and day length. For winter cereals, the roots become dormant after frost and resume their growth when the average air temperature exceeds the minimum required air temperature. The PTU were derived on the basis of unpublished planting, harvesting and general phenological data from variety trials in central Belgium (Veredelingsstation Heverlee [now out of use], data available from author). Crop characteristics and parameters were linked to the different growth stages and expressed in thermal time as a fraction of the required PTU (Table 2).

The water balance is a single-layer varying size bucket model, adapted from Allen et al. (1998) to incorporate effects of reduced growth conditions due to water stress (drought, water logging) or heat stress (temperature, VPD) on crop growth. Crop characteristics include rooting depth, crop factors linking AET to reference evapotranspiration, crop cover and the fraction of plant available water (depletion factor). The critical moisture content $\left(\theta_{\mathrm{CR}}\right)$, or the point below which restricted plant transpiration takes place, depends on the plant-specific depletion factor and varies with rooting depth. Water stress is defined as the number of days and amount of deficit with respect to the critical moisture level or as surplus with respect to field capacity $\left(\theta_{\mathrm{FC}}\right)$ and saturation $\left(\theta_{\mathrm{SAT}}\right)$. Crop stress is calculated as the degree of waterlogging $\left(\mathrm{WL}_{t}\right)$ or drought $\left(\mathrm{DR}_{t}\right)$ for a period of $10 \mathrm{~d}$ :

$$
\begin{gathered}
\mathrm{WL}_{t}=\frac{1}{10} \sum_{i=0}^{9}\left(\frac{\theta_{t-i}-\theta_{\mathrm{FC}}}{\theta_{\mathrm{SAT}}-\theta_{\mathrm{FC}}}\right) \text { for } \theta_{t-i}>\theta_{\mathrm{FC}} \\
\mathrm{DR}_{t}=\frac{1}{10} \sum_{i=0}^{9}\left(\frac{\theta_{t-i}-\theta_{\mathrm{WP}}}{\theta_{\mathrm{CR}}-\theta_{\mathrm{WP}}}\right) \text { for } \theta_{t-i}<\theta_{\mathrm{CR}}
\end{gathered}
$$

The actual evapotranspiration $\left(\mathrm{AET}_{t}\right)$ is a function of soil evaporation, plant transpiration and soil moisture. The soil evaporation factor $\left(K_{e t}\right)$ is calculated from the rainfall interval $\left(\mathrm{RI}_{t}\right)$ and the reference evapotranspiration, multiplied by the fraction of bare soil, taken as the reverse of the cropped soil $\left(C_{c}\right)$. Plant transpiration depends on the plant variety, growth stage and climatic zone. Crop-specific $K_{c b}$ factors (Eq. 7; Table 1) were adjusted for wind speed, relative humidity and plant height, resulting in higher transpiration rates for the majority of cases (Allen et al. 1998).

$$
\mathrm{AET}_{t}=\left(K_{c b t}+K_{e t}\right) \mathrm{PET}_{t}
$$

$K_{e t}=\left[1.286-0.274 \times \ln \left(\mathrm{RI}_{t}\right)-0.162 \ln \left(\mathrm{PET}_{t}\right)\right] \times\left(1-C_{c}\right)$

Ratios of AET and PET rates differ from $K_{c b}$ factors (Piccinni et al. 2009, Kjaergsaard et al. 2008), as they are mainly designed for irrigated crops and, hence, may not take into account plant physiological behaviour under drought conditions. To allow for reduced transpiration under drought stress, Eq. (2) was run in parallel and used when the soil moisture $\left(\theta_{t}\right)$ was below the critical moisture level $\left(\theta_{\mathrm{CR}}\right)$.

The regional dynamic biomass model was adapted from the Monteith \& Moss (1977) approach to incorporate extremes in soil moisture, temperature and vapour pressure. The photosynthetic active radiation (Monsi \& 
Saeki 1953) as a function of radiation ( $\mathrm{RAD}, \mathrm{MJ} \mathrm{m}^{-2}$ ) and leaf area index (LAI) was converted into potential daily increase in biomass using a light-use efficiency factor (LUE) (Table 2) and accounting for the effects of day length (DL) (after Monteith \& Moss 1977):

$$
\Delta B_{t}=\mathrm{LUE} \times 0.5 \times \mathrm{RAD}_{t} \times\left(1-\mathrm{e}^{-0.65 \mathrm{LAI}}\right) \times \mathrm{DL}_{t} \times R_{t}
$$

Temperature, water supply and vapour pressure are the main climatic constraints on crop growth efficiency.

The reduction factor $\left(R_{t}\right)$ is computed as the minimum of 4 climatic constraints for crop growth-waterlogging (WL, Eq. 5), drought (DR, Eq. 6), temperature stress (TR) or stress due to vapour pressure deficit (VPDR):

$$
\begin{gathered}
\mathrm{TR}_{t}=\frac{1}{3} \sum_{i=0}^{2} \sin \left(\frac{\pi}{2}\left[1-\frac{\left(T_{t-i}-T_{\mathrm{o}}\right)}{\left(T_{\max }-T_{\mathrm{o}}\right)}\right]\right) \\
\mathrm{VPDR}_{t}=\frac{1}{3} \sum_{i=0}^{2} \sin \left(\frac{\pi}{2}\left[1-\frac{\left(\mathrm{VPD}_{t-i}-\mathrm{VPD}_{\mathrm{o}}\right)}{\left(\mathrm{VPD}_{\max }-\mathrm{VPD}_{\mathrm{o}}\right)}\right]\right) \\
R_{t}=\min \left(\mathrm{WL}_{t}, \mathrm{DR}_{t}, \mathrm{TR}_{t}, \mathrm{VPDR}_{t}\right)
\end{gathered}
$$

This is incorporated in the VPD reduction term by setting $\mathrm{VPD}_{\mathrm{o}}$ to $0.9 \mathrm{kPa}$ and $\mathrm{VPD}_{\max }$ to $2 \mathrm{kPa}$.

Negative values result in zero additional growth in biomass; the maximum value for $R_{\mathrm{t}}$ equals 1 . Temperature stress reflects the physiological behaviour with respect to crop-specific optimal $\left(T_{\mathrm{o}}\right)$, maximum $\left(T_{\max }\right)$ and base temperatures $\left(T_{\mathrm{b}}\right)$ (Table 2$)$. The reduction term for VPD (Eq. 9) was developed to reflect the response of the crop to humidity. Values below $0.45 \mathrm{kPa}$ reflect a cool and humid environment, and values above $1.25 \mathrm{kPa}$ a hot and dry environment; optimal growth is considered to be around $0.9 \mathrm{kPa}$. VPD values above $2 \mathrm{kPa}$ have been reported as the breakpoint for transpiration rates (Fletcher et al. 2007, Rodriguez \& Sadras 2007).

The leaf area index (LAI) is an important structural property of the crop canopy that influences water interception, photosynthesis, respiration and senescence. The leaf area is reduced by stresses related to temperature, moisture and vapour pressure. The LAI curve (Williams et al. 1989) is adapted to incorporate growth reduction factors. Based on 2 scaling factors the temperature unit index (TUI) and the temperature unit factor (TUF) - LAI follows a sigmoid curve until the crop reaches its maximum at $80 \%$ of PTU:

$$
\begin{gathered}
\text { for } \mathrm{TUI}_{t}=\frac{\sum_{t=0}^{t} \mathrm{TU}_{t}}{\mathrm{PTU}} \leq 0.8: \mathrm{TUF}_{t}=\frac{\mathrm{TUI}_{t}}{\mathrm{TUI}_{t}+\exp \left(a-b \times \mathrm{TUI}_{t}\right)} \\
\Delta \mathrm{LAI}_{t}=\Delta \mathrm{TUF}_{t} \times \mathrm{LAI}_{\max } \times R_{t}
\end{gathered}
$$

After reaching its maximum, a power function describes the decline at the onset of senescence or at the grain filling stage in cereals: for $\mathrm{TUI}_{t}=\frac{\sum_{t=0}^{t} \mathrm{TU}_{t}}{\mathrm{PTU}}>0.8, \mathrm{LAI}_{t}=\mathrm{LAI}_{a t 0.8}\left(\frac{1-\mathrm{TUI}_{t}}{1-0.8}\right)^{0.2}$

The biomass generation part of the crop growth model provides a feedback mechanism (Eq. 16) to adjust leaf area development and hence actual crop cover $\left(C_{C}\right)$, refining the partitioning between covered and uncovered soil:

$$
C_{C}=1-\mathrm{e}^{-0.65 \mathrm{LAI}_{t}}
$$

The water balance returns information to the crop growth module concerning water stress in terms of waterlogging and soil-moisture deficit and accounting for the water-use efficiency.

Both the standing and root biomass are derived from the daily biomass growth $\left(\Delta B_{t}\right)$.

$$
\mathrm{BAG}_{t}=\mathrm{BAG}_{t-1}+(0.6+0.2 \mathrm{TUI}) \Delta B_{t}
$$

The yield is subsequently derived from the standing biomass (BAG, Eq. 17) before senescence occurs, using a harvest index ( $\mathrm{HI}$; Table 2). Calculations were made with nested iterations to close the energy balances and conserve the mass balance. Reported national yields provide for an assessment of the model's performance using model efficiency criteria such as the NashSutcliffe efficiency (Nash \& Sutcliffe 1970) and related indicators (Willmott 1981).

\subsection{Yield projections under climate scenarios}

According to global climate model predictions, Belgium is situated on the boundary between wetter and drier climatic regimes. Three climate-change scenarios were selected on the basis of a multi-criteria analysis (Ntegeka et al. 2008) of the PRUDENCE RCM runs (Christensen \& Christensen 2007), capturing the future climate variability in Belgium (Fig. 1). Goodness-offit between observed meteorological data and control runs for rainfall, temperature and evaporation were used to retain low (RCM: Arpège with GCM: HadCM3-B2), medium (RCM: RCAO with GCM: HadAM3H-B2) and high (RCM: RCAO with GCM: ECHAM4/OPYC-B2) scenarios. For the 3 selected PRUDENCE RCM runs, all meteorological variables were obtained using Interactive Data Language scripts for the grid nearest to Ukkel (central Belgium), which has the longest meteorological time series, beginning in 1833, and is located in the centre of the most productive agricultural area in Belgium.

Yield changes under climate-change scenarios were compared to simulations with observed meteorological data using simulated net primary production (NPP) divided by potential NPP in the case of summer crops and using simulated BAG divided by potential BAG in the case of winter cereals. Potential NPP and potential 

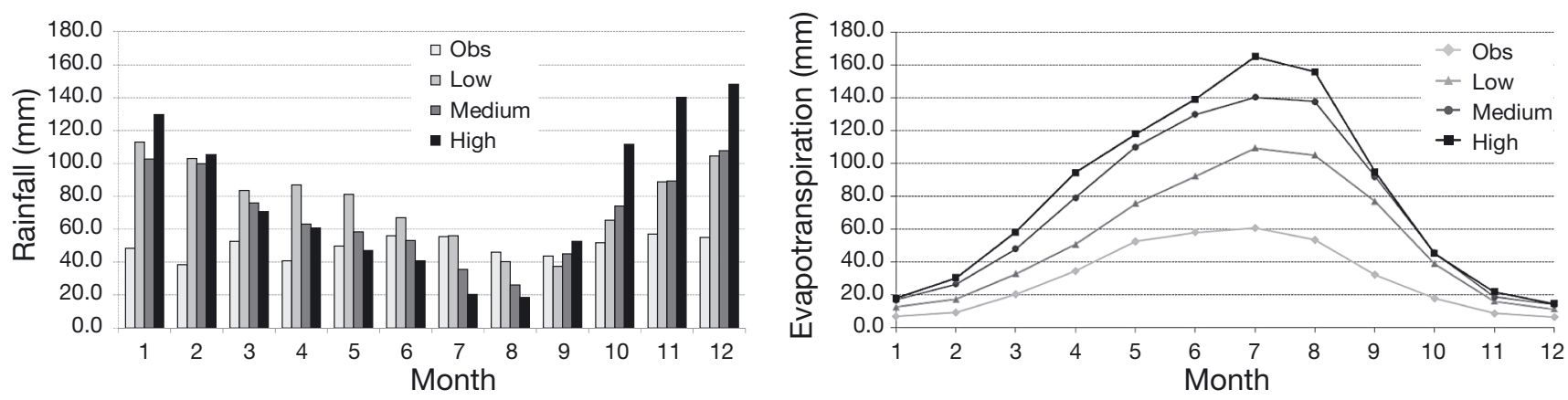

Fig. 1. Rainfall (left) and Penman-Monteith evapotranspiration (right) for 3 climate-change scenarios (low, medium and high) compared with 1960-1989 observations (Obs)

BAG were simulated without limiting reduction factors. Average yield reductions were calculated as the fraction of actual over potential biomass production (BAG, NPP) per major soil type for each climate change scenario and divided by the historical yield fractions. The yield reductions (or increases) were subsequently weighted according to the proportional division of agricultural parcels on each of the major soil types, as derived on the basis of the 2008 land parcel information system (LPIS) database. According to LPIS, the relative proportion of loamy sand:loam:clay is 12:62:26 for winter cereals, 10:74:16 for sugar beet and for 33:57:10 potatoes.

Yield reduction indicators were developed to evaluate yield changes on the basis of yield reduction factors (Eq. 12). The yield fraction of actual yield $\left(Y_{\text {act }}\right)$ over potential yield $\left(Y_{\text {pot }}\right)$ was also expressed as the product of a sequence of terms based on the reduction factor $\left(R_{t}\right)$ and a sensitivity factor $\left(k_{s t i}\right.$ Table 2$)$ in order to weight for sensitive crop stages during the growth season (S, d; Eq. 18):

$$
\frac{Y_{\mathrm{act}}}{Y_{\mathrm{pot}}}=\prod_{t=1}^{S}\left[1-k_{\mathrm{st}}\left(1-R_{t}\right)\right]^{1 / S}
$$

The effects of temperature and water stress were accounted for separately by replacing $R_{t}$ in Eq. (18) with $\mathrm{WL}_{t}$ (Eq. 5), $\mathrm{DR}_{t}$ (Eq. 6), TR $t$ (Eq. 10) or $\mathrm{VPDR}_{t}$ (Eq. 12), thus resulting in different yield reduction indicators that enable quantification of the distance between actual and potential yields due to different stress types. Changing atmospheric $\mathrm{CO}_{2}$ concentrations, which can be related to an increase in light-use efficiencies, have not been taken into account.

\section{RESULTS}

\subsection{Weather and yield observations}

The frequency and magnitude of extreme weather events are likely to increase with climate change. In
Belgium, the past 2 decades have experienced more monthly extremes than any other decade since the observations started in 1833 (Fig. 2).

Results of detrending show a high goodness-of-fit between Belgian yields and time; $\mathrm{R}^{2}$ varied from 0.79 for sugar beet to 0.94 for winter barley (Fig. 3). During the past $60 \mathrm{yr}$, yields increased at a mean \pm SE rate of $0.102 \pm 0.004 \mathrm{t} \mathrm{ha}^{-1} \mathrm{yr}^{-1}$ for winter wheat, $0.095 \pm$ $0.003 \mathrm{t} \mathrm{ha}^{-1} \mathrm{yr}^{-1}$ for winter barley, $0.440 \pm 0.025 \mathrm{t} \mathrm{ha}^{-1}$ $\mathrm{yr}^{-1}$ for potatoes and $0.580 \pm 0.038 \mathrm{t} \mathrm{ha}^{-1} \mathrm{yr}^{-1}$ for sugar beet. Yields differed significantly $(p<0.001)$ between the 2 climate periods (0: pre 1987, 1: 1988-2008). Yield residuals did not significantly differ between the 2 climate periods ( $p=0.44$ to 0.82 ). High correlations between arable crop yields and meteorological variables integrated over the cropping season (Table 3) show significant correlations between yield and the temperature-related variables VPD, PET, THU and $T_{\min }$, low rainfall and soil moisture conditions. Moreover, these meteorological variables are significantly different between the 2 climate periods (Table 4 ), and appear to reflect the long-term meteorological variability or climate condition. Correlations between yield residuals and meteorological variables (Table 3) demonstrate the importance of the water balance (Eq. 2), the maximum of $T_{\max }$, soil-moisture conditions and average rainfall. The majority of these meteorological variables, as well as the yield residuals, are not significantly different between the 2 climate periods and appear to capture short-term meteorological conditions or interannual weather variability. These results suggest that detrending yields prior to investigating climate impacts might have accentuated interannual weather variability, but might have removed all or part of the long-term climate variability alongside the effects of technological developments.

The hypothesis that weather conditions have a substantial impact on crop yield in Belgium was tested by analysing statistical relationships between yield and meteorological variables. Principal component analysis confirmed multi-collinearity among the meteoro- 

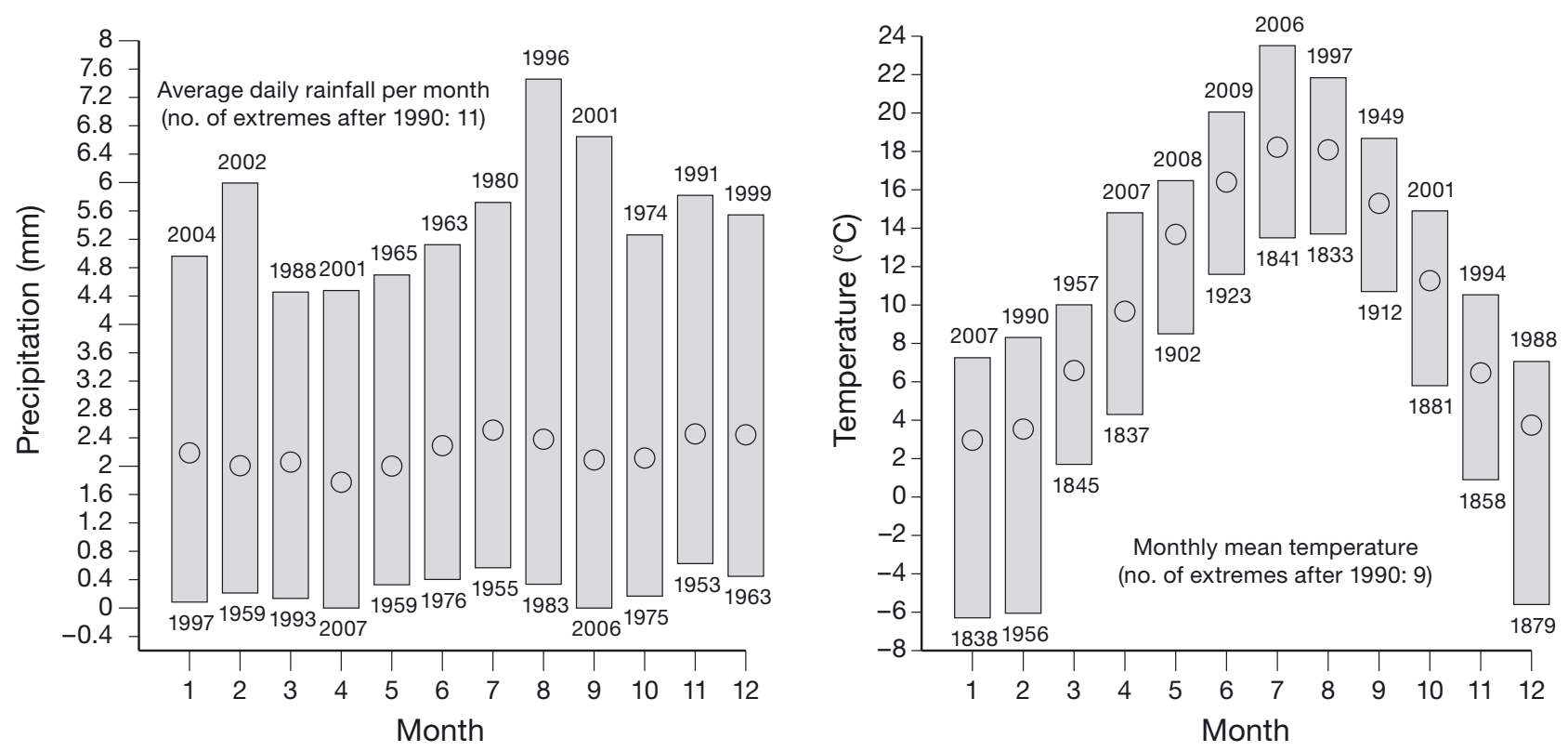

Fig. 2. Monthly precipitation and temperature, median (circles) and extremes at Ukkel since 1833. Labels indicate years with monthly extreme(s) (RMI 2009)
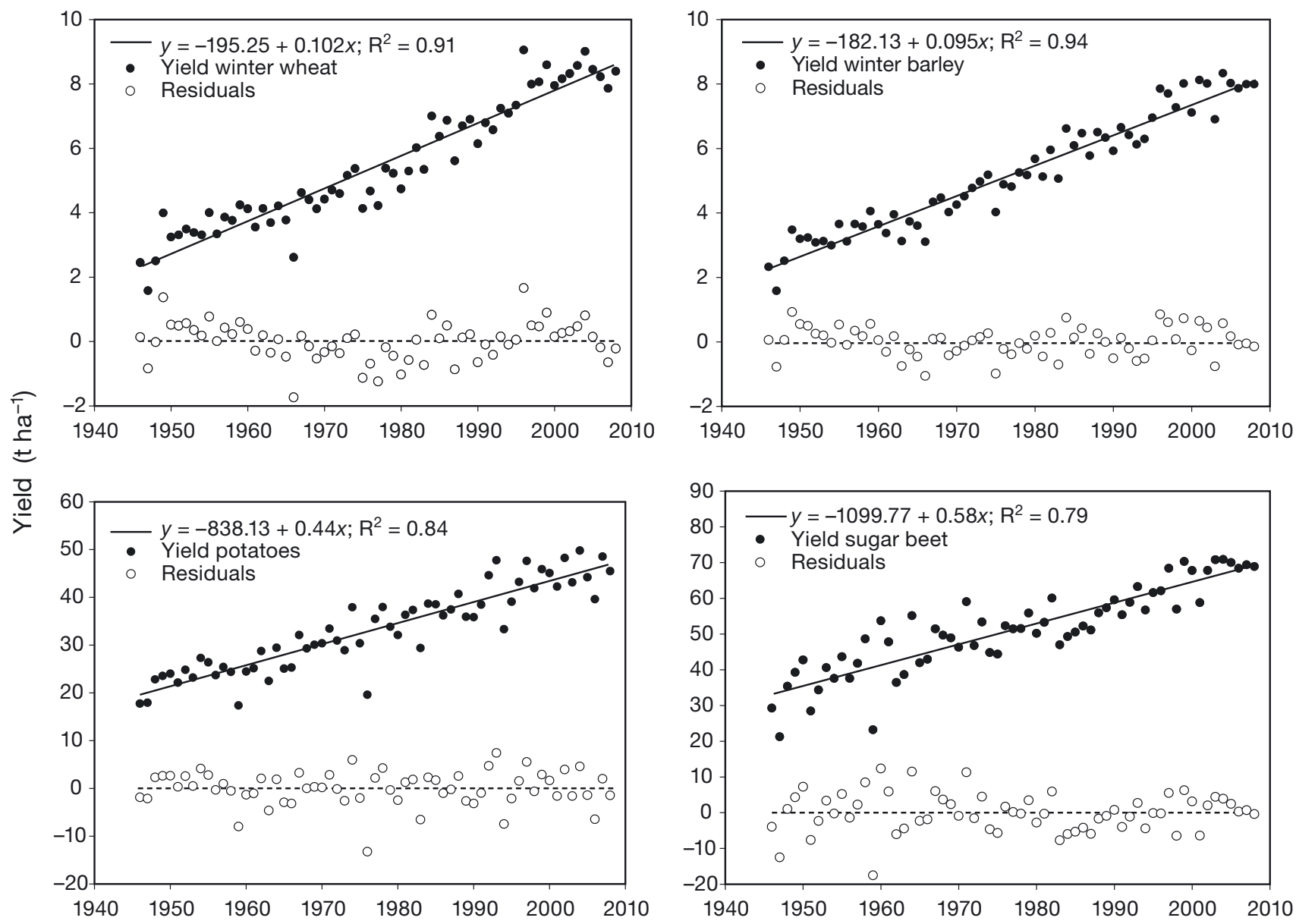

Fig. 3. Time series (1947-2008) of observed and detrended yield of 4 Belgian arable crops 
Table 3. Correlation coefficients of yield and yield residuals with meteorological variables, aggregated during the growing season of 4 arable crops (top 5 rank). VPD: vapour pressure deficit; PET: potential evapotranspiration; TU: thermal units; $T_{\min }$ and $T_{\max }$ : minimum and maximum temperature, respectively; P: rainfall. Significant at $p<0.05$, unless otherwise stated (ns: not significant)

\begin{tabular}{|c|c|c|c|c|c|c|c|c|}
\hline \multirow{2}{*}{$\begin{array}{l}\text { Meteorological variable } \\
\text { Yield }\end{array}$} & \multicolumn{2}{|c|}{ Winter wheat } & \multicolumn{2}{|c|}{ Winter barley } & \multicolumn{2}{|c|}{ Potato } & \multicolumn{2}{|c|}{ Sugar bee } \\
\hline & & & & & & & & \\
\hline Days with VPD $>0.5 \mathrm{kPa}$ & 0.83 & (1) & 0.78 & (2) & 0.71 & (1) & 0.66 & (1) \\
\hline$\Sigma \mathrm{PET}$ & 0.67 & (2) & 0.66 & (3) & 0.32 & & 0.34 & \\
\hline Average wind speed & -0.67 & (3) & -0.66 & (4) & -0.69 & (2) & -0.66 & (2) \\
\hline$\Sigma \mathrm{TU}$ & 0.58 & (5) & 0.35 & & 0.37 & (4) & 0.38 & (4) \\
\hline Average $T_{\min }$ & 0.59 & (4) & 0.59 & (5) & 0.52 & (3) & 0.59 & (3) \\
\hline$\Sigma$ (Days with $\mathrm{P}<0.2 \mathrm{~mm}$ ) & 0.43 & & 0.83 & (1) & 0.08 & ns & 0.17 & ns \\
\hline$\Sigma$ (Days with $\mathrm{P}>15 \mathrm{~mm}$ ) & 0.10 & ns & -0.03 & ns & 0.36 & $(5)$ & 0.37 & $(5)$ \\
\hline$\Sigma$ (Waterlogged conditions days) & -0.37 & & -0.37 & & -0.18 & ns & -0.19 & ns \\
\hline$\Sigma$ (Wet moisture conditions days) & 0.33 & & 0.32 & & 0.31 & & 0.28 & \\
\hline$\Sigma$ (Dry moisture conditions days) & 0.23 & ns & 0.15 & ns & 0.00 & ns & 0.00 & ns \\
\hline$\Sigma$ (Radiation) & -0.23 & & -0.31 & & -0.36 & & -0.36 & \\
\hline \multicolumn{9}{|l|}{ Yield residuals } \\
\hline$\Sigma$ (Radiation) & 0.44 & (1) & 0.32 & (1) & 0.03 & ns & 0.02 & ns \\
\hline$\Sigma$ (Days with dry water balance) & 0.40 & (2) & 0.18 & ns & -0.18 & ns & -0.28 & (5) \\
\hline$\Sigma($ Days with $\mathrm{P}<0.2 \mathrm{~mm})$ & 0.37 & (3) & 0.20 & ns & -0.32 & (2) & -0.37 & $(2)$ \\
\hline$\Sigma($ Rainfall $)$ & -0.36 & (4) & -0.13 & ns & 0.28 & (4) & 0.37 & (3) \\
\hline$\Sigma$ (Days with wet water balance) & -0.31 & (5) & -0.16 & ns & 0.18 & ns & 0.27 & \\
\hline$\Sigma\left(\right.$ Days with $\left.T_{\max }>30^{\circ} \mathrm{C}\right)$ & -0.05 & ns & -0.02 & ns & -0.46 & (1) & -0.46 & (1) \\
\hline$\Sigma($ Days with $\mathrm{P}>15 \mathrm{~mm})$ & -0.27 & & -0.18 & ns & 0.21 & ns & 0.21 & ns \\
\hline$\Sigma$ (Dry moisture condition days) & 0.27 & & 0.04 & ns & -0.32 & (3) & -0.36 & (4) \\
\hline
\end{tabular}

logical variables. The first principal component axis (PC1) explained $42.9 \%$ of the variation in meteorological variables and revealed high loadings from temperature and VPD, THU and PET. PC2 explained $17.3 \%$ of the variation and had high loadings from rainfall, water balance and soil-moisture-related variables. PC1 and PC2 significantly differed between the 2 climate groups ( $p<0.001)$. For each crop, 2 non-collinear variables with high correlations with yield (Table 3 ) and significant differences between the 2 climate periods were selected (Table 4): the sum of days with VPD $>0.5 \mathrm{kPa}$; the sum of days with rainfall $<0.2 \mathrm{~mm}$, in the case of winter cereals; and the sum of days with rainfall $>15 \mathrm{~mm}$, in the case of summer root crops.
Non-linear regressions explained $74 \%$ of the variability in winter wheat yield, $73 \%$ in winter barley, $70 \%$ in potatoes and $60 \%$ in sugar beet, which demonstrates the effect of the selected meteorological variables on yield. A variance-minimizing non-hierarchical (k-means) cluster analysis involving the selected meteorological variables demonstrates that there was a significant effect of days with VPD $>0.5(\mathrm{p}<0.001)$ on the separation of clusters for each of the crops. Days with rainfall $<0.2 \mathrm{~mm}$ significantly $(p<0.001)$ influenced the clustering of winter cereal yields. For summer crops, the effect of days with rainfall $>15 \mathrm{~mm}$ was significant at $\mathrm{p}<0.025$.

Changes in single meteorological variables had a significant impact on yields. Linear regressions be-

Table 4. Comparison of yield and meteorological variables, aggregated during the growing season of 4 arable crops, for 2 climate periods (M0: 1947-1987; M1: 1988-2008). VPD: vapour pressure deficit; P: rainfall; TU: thermal units; PET: potential evapotranspiration; Tmin: minimum temperature. p-values: ${ }^{*}<0.05{ }_{i}{ }^{* *}<0.01 ;{ }^{* * *}<0.001 ;$ ns: not significant

\begin{tabular}{|c|c|c|c|c|c|c|c|c|}
\hline & & $\begin{array}{l}\text { Yield } \\
\left(\mathrm{t} \mathrm{ha}^{-1}\right)\end{array}$ & $\begin{array}{c}\text { Days with } \\
\text { VPD }>0.5 \mathrm{kPa}\end{array}$ & $\begin{array}{l}\text { Days with } \\
\mathrm{P}<0.2 \mathrm{~mm}\end{array}$ & $\begin{array}{l}\text { Days with } \\
\mathrm{P}>15 \mathrm{~mm}\end{array}$ & $\Sigma \mathrm{TU}\left({ }^{\circ} \mathrm{C}\right)$ & ¿PET (mm) & $\begin{array}{c}\text { Mean } \\
T_{\min }\left({ }^{\circ} \mathrm{C}\right)\end{array}$ \\
\hline Winter wheat & $\begin{array}{l}\text { M0 } \\
\text { M1 }\end{array}$ & $\begin{array}{l}4.35 \pm 1.12 \\
7.78 \pm 0.84^{* * *}\end{array}$ & $\begin{array}{l}49.9 \pm 22.8 \\
91.8 \pm 11.9^{* * *}\end{array}$ & $\begin{array}{l}132.6 \pm 18.0 \\
151.9 \pm 20.7^{* * *}\end{array}$ & $\begin{array}{l}6.0 \pm 3.3 \\
7.0 \pm 2.8(\mathrm{~ns})\end{array}$ & $\begin{array}{l}1651.4 \pm 116.6 \\
1910.0 \pm 138.8^{* * *}\end{array}$ & $\begin{array}{l}507.5 \pm 56.0 \\
597.8 \pm 40.8^{* * *}\end{array}$ & $\begin{array}{l}4.7 \pm 0.6 \\
6.0 \pm 0.7^{* * *}\end{array}$ \\
\hline Winter barley & $\begin{array}{l}\text { M0 } \\
\text { M1 }\end{array}$ & $\begin{array}{l}4.22 \pm 1.13 \\
7.25 \pm 0.79^{* * *}\end{array}$ & $\begin{array}{l}41.3 \pm 19.1 \\
76.5 \pm 10.6^{* * *}\end{array}$ & $\begin{array}{l}122.0 \pm 17.0 \\
138.5 \pm 19.5^{* * *}\end{array}$ & $\begin{array}{l}5.3 \pm 3.1 \\
6.4 \pm 2.9(\mathrm{~ns})\end{array}$ & $\begin{array}{l}1385.1 \pm 112.0 \\
1610.7 \pm 139.8^{* * *}\end{array}$ & $\begin{array}{l}445.8 \pm 50.1 \\
521.3 \pm 33.6^{* * *}\end{array}$ & $\begin{array}{l}4.2 \pm 0.6 \\
5.5 \pm 0.7^{* * *}\end{array}$ \\
\hline Potatoes & $\begin{array}{l}\text { M0 } \\
\text { M1 }\end{array}$ & $\begin{array}{l}28.75 \pm 5.95 \\
42.86 \pm 4.58^{* * *}\end{array}$ & $\begin{array}{c}64.3 \pm 32.0 \\
110.1 \pm 10.4^{* * *}\end{array}$ & $\begin{array}{l}79.5 \pm 13.2 \\
89.9 \pm 13.0^{* *}\end{array}$ & $\begin{array}{l}3.7 \pm 2.3 \\
5.2 \pm 2.0^{*}\end{array}$ & $\begin{array}{l}1327.6 \pm 125.2 \\
1483.3 \pm 89.9^{* * *}\end{array}$ & $\begin{array}{l}490.6 \pm 64.5 \\
556.3 \pm 38.0^{* * *}\end{array}$ & $\begin{array}{l}10.0 \pm 0.6 \\
11.1 \pm 0.7^{* * *}\end{array}$ \\
\hline Sugar beet & $\begin{array}{l}\text { M0 } \\
\text { M1 }\end{array}$ & $\begin{array}{l}45.34 \pm 8.79 \\
63.72 \pm 5.73^{* * *}\end{array}$ & $\begin{array}{c}68.5 \pm 35.3 \\
119.8 \pm 12.3^{* * *}\end{array}$ & $\begin{array}{c}94.9 \pm 14.8 \\
106.6 \pm 14.9^{* *}\end{array}$ & $\begin{aligned} 4.6 & \pm 2.5 \\
6.2 & \pm 2.4^{*}\end{aligned}$ & $\begin{array}{l}1709.5 \pm 144.2 \\
1872.3 \pm 108.5^{* * *}\end{array}$ & $\begin{array}{l}538.2 \pm 68.5 \\
610.3 \pm 42.9^{* * *}\end{array}$ & $\begin{array}{c}9.8 \pm 0.6 \\
10.9 \pm 0.7^{* * *}\end{array}$ \\
\hline
\end{tabular}



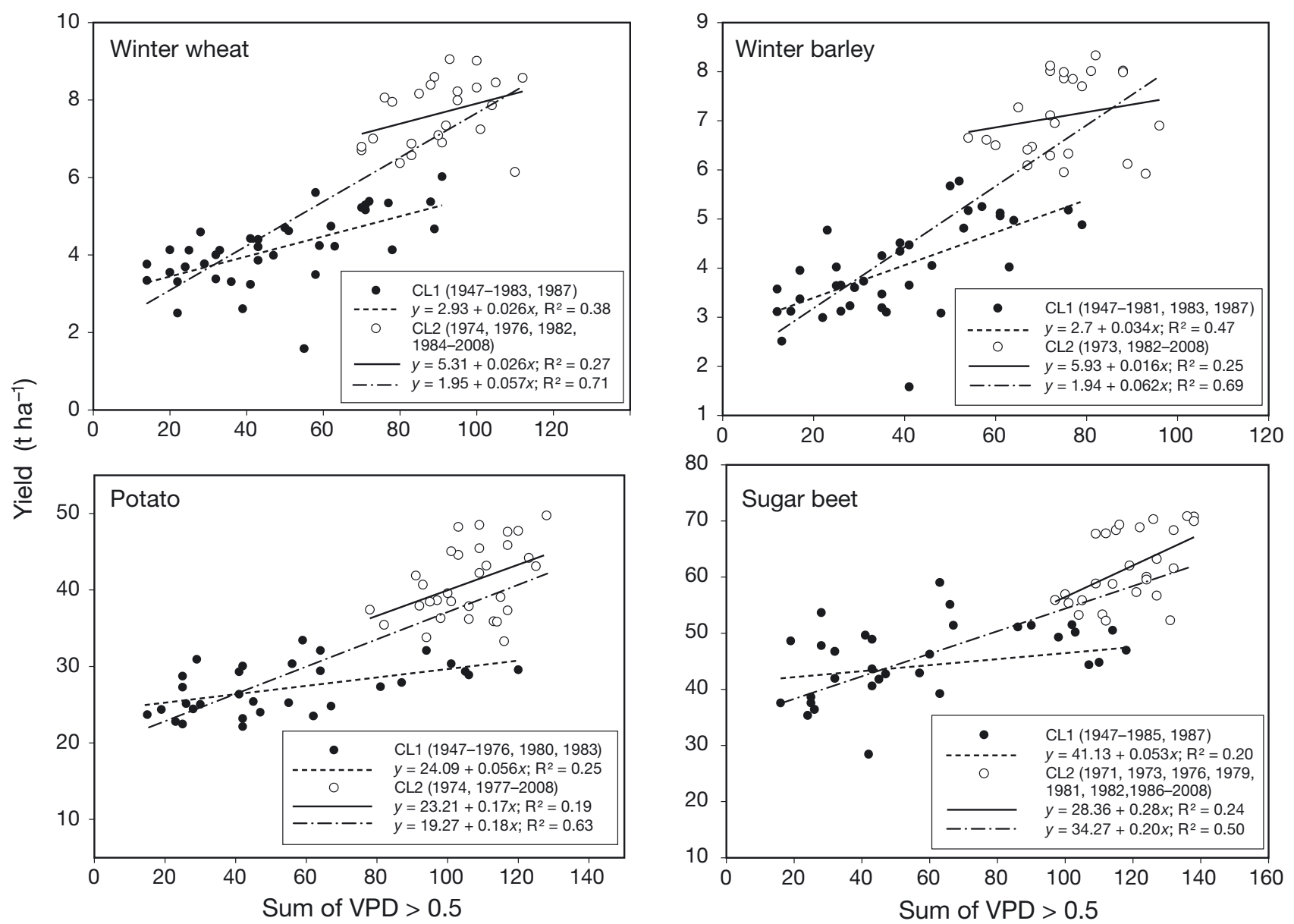

Fig. 4. Linear regression between arable crop yield $\left(\mathrm{t} \mathrm{ha}^{-1}\right)$ and days with VPD $>0.5$. Clustering is based on days with VPD $>0.5$ and rainfall days above $15 \mathrm{~mm}$ for summer root crops or rainfall days below $0.2 \mathrm{~mm}$ for winter cereals

tween yields and growing days with VPD $>0.5$ (Fig. 4) revealed that the form of the relationship did not significantly change between the 2 different climate periods. Rates of yield increase per growing day with VPD $>0.5 \mathrm{kPa}$ were not significantly different between the clusters; the intercept of the regression, however, was significantly different between the clusters. The results confirm that the majority of climate impacts took place between the 1970s and 1980s, with increasingly more years belonging to a warmer climatic regime.

\subsection{REGCROP model output}

Not only the frequency and magnitude of meteorological events, but also their timing in relation to crop development will determine their effects. The REGCROP model output shows that yields are simulated well, with a tendency to slightly overestimate with a relative difference of 0.5 to $4 \%$ between observed and simulated yields (Table 5). The Nash-
Sutcliffe efficiency was highest for sugar beet $(0.84)$ and lowest for winter wheat $(0.68)$. The simulated winter cereal yields accounted for $80 \%$ of the variation in the observed yields (Fig. 5). Overall, winter cereal yields were overestimated, with an overprediction of the lower yields. Simulated sugar beet yields captured $84 \%$ of the variation in observed yields, with an overestimation of lower yields. The simulated potato yields accounted for $83 \%$ of the variation in observed yields; lower potato yields were overestimated and higher yields were underestimated.

On the basis of detrending analysis (Fig. 3), years with yield residuals below the 10th percentile or above the 90th percentile were defined as extreme. The quantitative measures of model performance showed that the differences between simulated and observed yields are not the same for years with extreme yields as compared with normal years (Table 5). For all arable crops, the normal year simulations $\left(\mathrm{N}_{\text {; }}\right.$ Table 5) did not differ from the overall simulated years (All; Table 5), but they differed from the years 
Table 5. Quantitative measures of REGCROP model performance according to high, low and normal years. H: 90th percentile; L: 10th percentile; N: other yields; All: all years; Obs: mean observed yield ( $\left.\mathrm{t} \mathrm{ha}^{-1}\right)$; Sim: mean simulated yield ( $\mathrm{t} \mathrm{ha}^{-1}$ ); MBE: mean bias error; MAE: mean absolute error; RMSE: root mean square error; E: model efficiency; d: index of agreement

\begin{tabular}{|c|c|c|c|c|c|c|c|c|}
\hline Class & Obs & Sim & MBE & MAE & RMSE & E & $\mathrm{R}^{2}$ & d \\
\hline \multicolumn{9}{|c|}{ Winter wheat } \\
\hline All & 10.395 & 10.834 & 0.439 & 0.910 & 1.056 & 0.68 & 0.80 & 0.928 \\
\hline $\mathrm{H}$ & 12.808 & 13.072 & 0.264 & 0.550 & 0.668 & 0.93 & 0.72 & 0.985 \\
\hline $\mathrm{L}$ & 8.443 & 9.374 & 0.931 & 0.968 & 1.126 & 0.75 & 0.66 & 0.901 \\
\hline $\mathrm{N}$ & 10.501 & 10.868 & 0.367 & 0.937 & 1.076 & 0.61 & 0.79 & 0.920 \\
\hline \multicolumn{9}{|c|}{ Winter barley } \\
\hline All & 9.564 & 9.845 & 0.281 & 0.651 & 0.859 & 0.71 & 0.80 & 0.933 \\
\hline $\mathrm{H}$ & 11.510 & 11.768 & 0.258 & 0.958 & 1.155 & 0.66 & 0.46 & 0.932 \\
\hline L & 8.218 & 9.015 & 0.797 & 0.964 & 1.228 & 0.67 & 0.68 & 0.879 \\
\hline $\mathrm{N}$ & 9.467 & 9.668 & 0.201 & 0.551 & 0.719 & 0.74 & 0.85 & 0.945 \\
\hline \multicolumn{9}{|l|}{ Potato } \\
\hline All & 36.249 & 37.276 & 1.027 & 2.551 & 3.504 & 0.78 & 0.83 & 0.927 \\
\hline $\mathrm{H}$ & 44.814 & 43.702 & -1.112 & 1.605 & 2.066 & 0.95 & 0.86 & 0.987 \\
\hline $\mathrm{L}$ & 28.245 & 32.778 & 4.533 & 5.850 & 6.744 & 0.58 & 0.60 & 0.786 \\
\hline $\mathrm{N}$ & 35.918 & 36.776 & 0.858 & 2.185 & 2.881 & 0.79 & 0.82 & 0.936 \\
\hline \multicolumn{9}{|c|}{ Sugar beet } \\
\hline All & 55.574 & 55.876 & 0.302 & 2.764 & 3.558 & 0.84 & 0.84 & 0.957 \\
\hline $\mathrm{H}$ & 57.886 & 57.680 & -0.206 & 3.373 & 4.144 & 0.656 & 0.68 & 0.913 \\
\hline $\mathrm{L}$ & 49.654 & 52.998 & 3.344 & 3.449 & 4.846 & 0.762 & 0.81 & 0.916 \\
\hline $\mathrm{N}$ & 56.037 & 56.014 & -0.023 & 2.598 & 3.270 & 0.868 & 0.87 & 0.965 \\
\hline
\end{tabular}

$(\mathrm{p}=0.05)$ and WL $(\mathrm{p}=0.05)$. Model performances for extreme summer root crops were different from normal years (Table 5); differences in mean and absolute error between normal and low-yielding years were significant (potato, $\mathrm{p}=0.02$; sugar beet, $\mathrm{p}=$ 0.04), but not for the high-yielding years $(p>0.05)$. High and low potato yields were related to significant differences in the yield reduction indicators for temperature $(p=0.05)$ and VPD $(p=0.004)$. Extreme sugar beet yields differed significantly in yieldreduction indicators for temperature $(p=0.01)$ and VPD $(p=0.05)$. Differences between simulated and observed yields were the same in years with extreme and normal yields, with the exception of low tuber crop yields.

\subsection{Effects of climate change}

Although yearly balances fail to reflect seasonal dry spells or soil water with extreme yields. Model performances for extreme winter cereal yields were different from normal years (Table 5), but differences in mean and absolute error were not significant at the 0.05 level. In the case of winter wheat, differences between high- and lowyielding years were linked to significant differences in different yield reduction indicators for temperature $(p=0.05)$, VPD $(p=0.044)$ and WL $(p=0.04)$. Differences between high and low winter barley yields could be linked to significant differences in the yield reduction indicators for temperature $(p=0.04)$, VPD storage, a comparison between scenarios or between crops under a certain climate scenario provides an indication of water shortage and surplus (Fig. 6). Summer root crops experience increased drought stress, particularly when the sensitive crop stages coincide with dry spells. Yields may be further reduced when wet springs cause water logging in the field and delay planting dates. Rising temperatures enable earlier maturity of winter cereals, which, in turn, will reduce yield reductions due to drought stress or increased heat stress during the flowering period. Despite lower
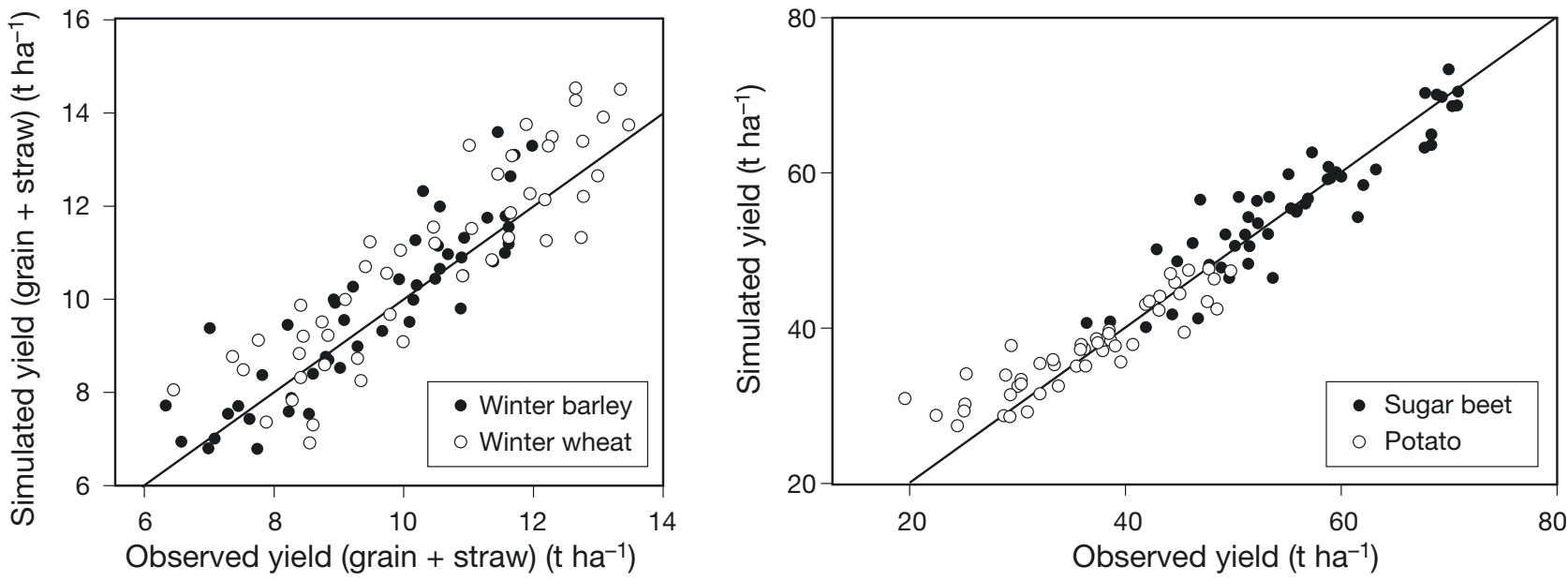

Fig. 5. Simulated versus observed yields for winter cereals (left) and summer root crops (right) 

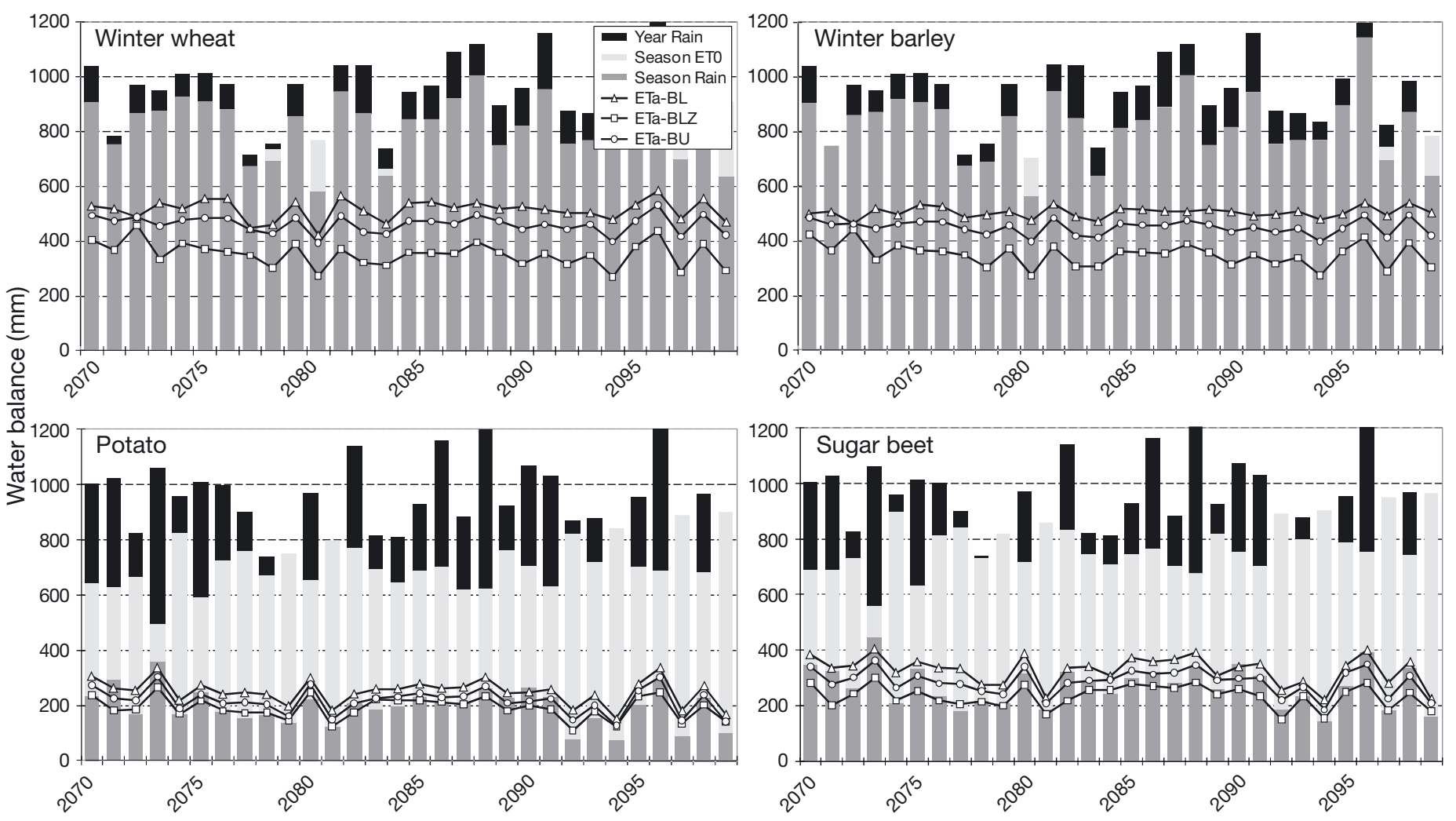

Fig. 6. Water balance components for arable crops on 3 typical Belgian soils (BL: Belgian loam; BLZ: Belgian loamy sand; BU: Belgian clay) for the high climate-change scenario. ET0: potential evapotranspiration (PET); ETa: actual evapotranspiration (AET)
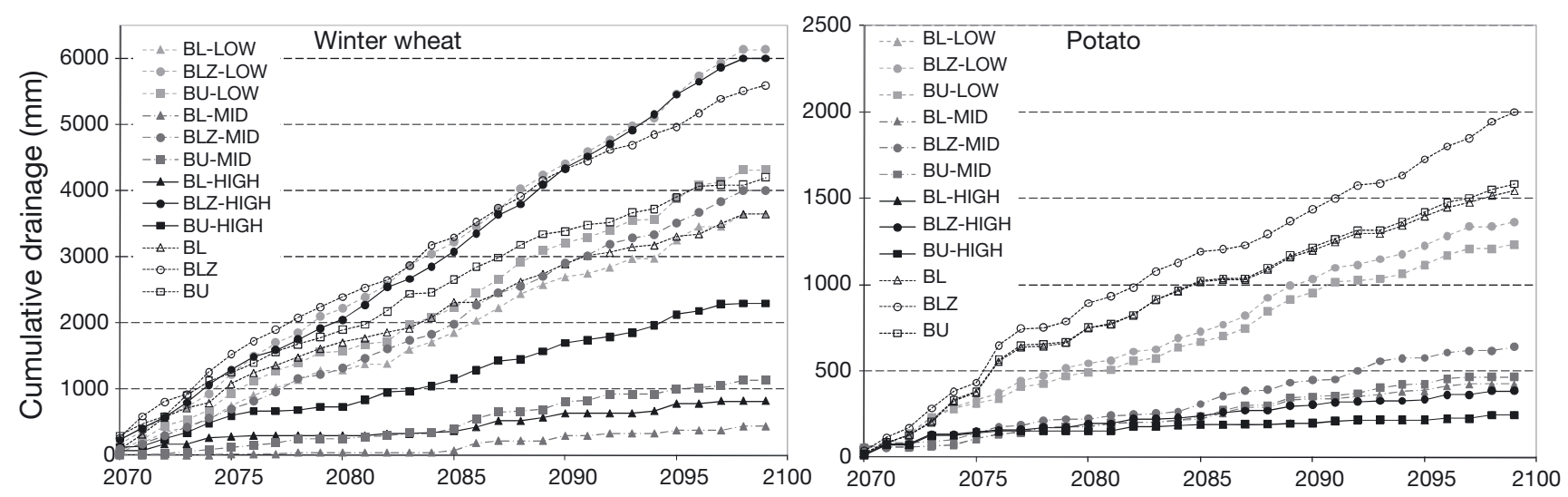

Fig. 7. Cumulative drainage for winter wheat (left) and potato (right) under 3 typical Belgian soils (loamy sand, loam and clay) for 3 climate-change scenarios (2070-2099; low, medium and high) and observed weather conditions (1960-1989), projected on the same axis

summer precipitation predictions for future climate in Belgium, winter cereals may suffer from water logging in the field, particularly during early spring, which is the case for the low climate-change scenario.

Strong projected changes in seasonality (Fig. 1) affect cumulative drainage for both winter and summer crops. Despite projections of higher winter precipita- tion, drainage under winter cereals is expected to decrease in heavy textured soils (clay and loam soils in Fig. 7). Rising temperatures cause higher evapotranspiration rates and result in a drier water balance regime with climate change. Only for sandy soils was a higher drainage under winter cereals simulated for the low and high climate-change scenarios as compared 

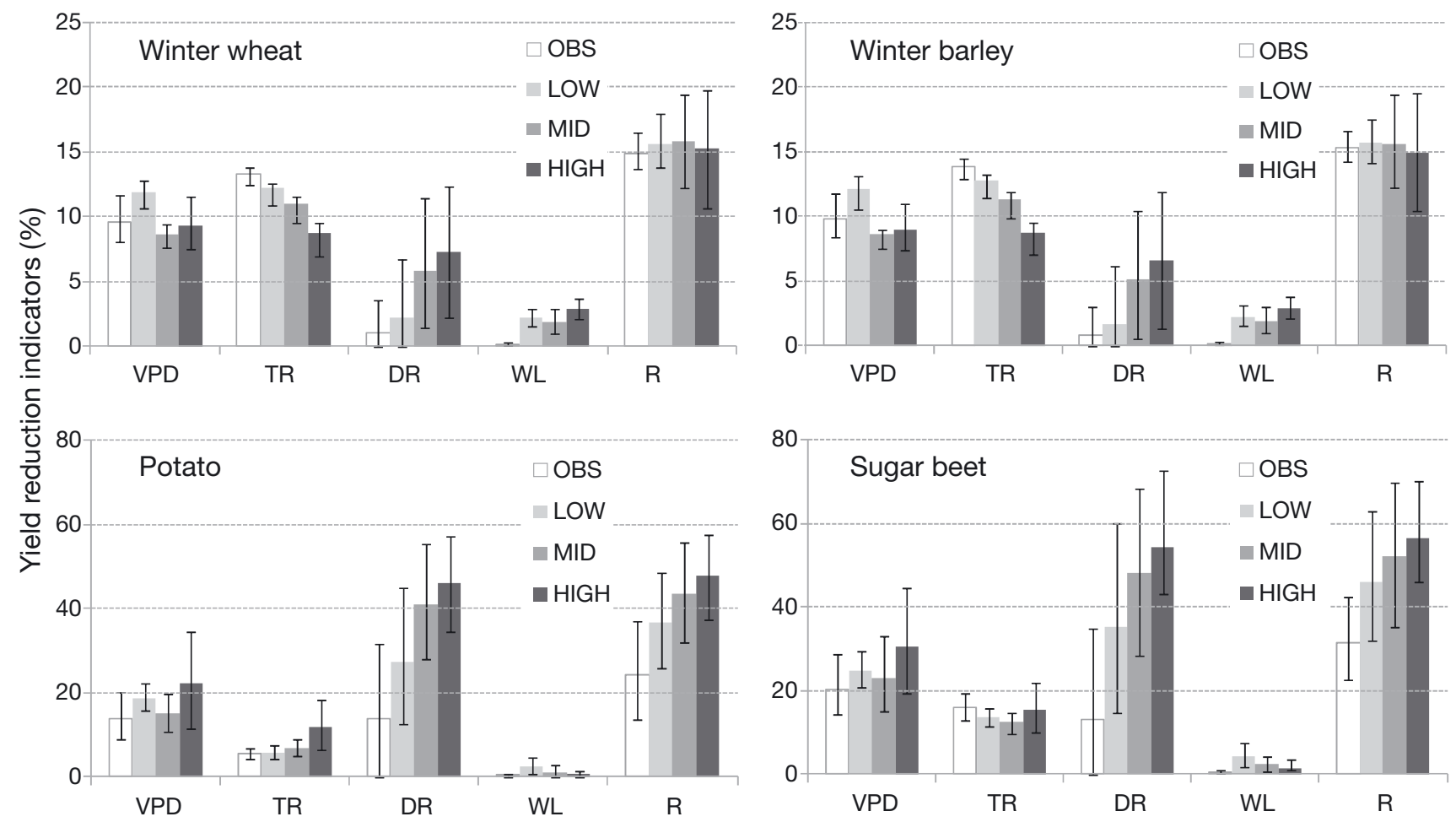

Fig. 8. Yield reduction indicators for arable crops under 3 climate-change scenarios (low, medium and high). Error bars indicate ranges as simulated for 3 typical Belgian soils (loamy sand, loam and clay). VPD: vapour pressure deficit; TR: temperature reduction; DR: drought reduction; WL: water logging; R: overall reduction

with the historical time series. This can be explained by high spring rainfall in the low climate-change scenario and high autumn rainfall in the high climatechange scenario (Fig. 1) in combination with high infiltration rates on sandy soils. For summer crops, the dual effect of rising temperatures and lower rainfall results in lower cumulative drainage under all scenarios of climate change, as compared with historical data (Fig. 7).

Yield reduction indicators (Fig. 8) show a favourable effect of VPD and higher temperatures on winter cereal yields; increased waterlogging in winter and early spring has negative effects on winter cereal yields. Poor summer root crop yields are attributed to drought in late spring and summer, and to higher summer temperatures, which cause heat stress. For the 3 climate change scenarios (low, medium, high), average yield losses of $12 \%$ (low), 17\% (medium) and $27 \%$ (high) were simulated for sugar beet and $23 \%$ (low), $37 \%$ (medium) and $44 \%$ (high) for potatoes as compared with historical yields. Projected losses were $5 \%$ for winter wheat and $12 \%$ for winter barley under a low climate-change scenario. Yield increases of $6 \%$ for winter wheat and $3 \%$ for winter barley were simulated for the medium scenario. For the high scenario, projected yield increases were $2 \%$ for winter wheat and $7 \%$ for winter barley.

\section{DISCUSSION}

Examples from other regions in the world have demonstrated the usefulness of detrending yields in relation to seasonal weather (e.g. agricultural insurances: Bielza et al. 2008) or climate variability (Nicholls 1997, Trnka et al. 2007, Baigorria et al. 2008) to amplify the interannual yield variations owing to weather factors and to control for technological advances such as improved varieties and management. The results of the present study demonstrate that climate and technological advances cannot easily be separated using detrending analysis. Yields differed significantly between the 2 climatic periods (pre- and post-1987) and were linked to meteorological variables; yield residuals, however, did not differ significantly. Yield trends contain information on the effects of climate variability. Technological advances might also indirectly result from climate change, such as improved varieties that allow for earlier sowing dates. Effects of climate and technological advances on annual yield rates are closely related but can be separated using data from variety trials, as demonstrated by Jaggard et al. (2007).

Understanding climate-yield relationships and the effects of recent climate trends on regional crop productivity is an important step in predicting agricultural 
production at the national scale (Lobell \& Asner 2003, Tao et al. 2008). Results from Europe confirm the effect of climate change on national agricultural production (Moonen et al. 2002, Chmielewski et al. 2004, Trnka et al. 2009). A total of 60 to $74 \%$ of the variability in Belgian arable crop yields is explained by meteorological variables during the growing season. At the Belgian national scale, higher winter cereal yields are attributed to higher temperatures, drier springs and more days with favourable VPD values. Low tuber crop yields, however, are caused by drought and heat stress. These findings are consistent with other research. By the time heat waves strike, winter sown cereals have terminated growth and are less affected by the summer drought, as confirmed by an analysis of the 2003 heat wave impact across Europe (Ciais et al. 2005). Tuber crop yields in extreme years tend to be highly variable: drought stress was the major factor causing yield loss of sugar beet (Pidgeon et al. 2001) and potato (Š́t'astná et al. 2010).

Yields were projected with the REGCROP model and effects were calculated for 4 arable crops in Belgium under 3 scenarios of climate change. Increased frequency of heat stress, drought and floods negatively affected yields. Analysis from several studies suggests that crops with the highest relative increases in yield are the most adaptable to interannual weather variability and climate change, with the best adapted crop being winter wheat and the least adapted potato. Under future climate scenarios, wheat may be resilient to drought but not heat stress (Semenov 2009). Potato (Holden et al. 2003) and sugar beet (P. D. Jones et al. 2003) yields will increasingly suffer from the effects of drought.

\section{CONCLUSIONS}

The sensitivity of agricultural yield variability to climate change depends on future technological progress, crop adaptation and meteorological effects, among many other factors. The results show that detrending yields prior to studying climate impacts may not capture all climatic trends. Multivariate analysis showed that there were significant statistical relationships between yield and VPD, temperature, growing season length, water logging and drought, and that these meteorological variables significantly differed between 2 climate periods. The meteorological variables were therefore included in a new regional dynamic crop model (REGCROP) developed to assess climate impacts on regional arable crop production. The model predicts historical yields well and is able to simulate extreme yields, which may approximate climate change conditions. The model can integrate the effects of cropping calendars, weather and soil on crop yields at the regional scale.

A drier water balance regime is projected with all the selected climate-change scenarios. Pronounced yield losses, mainly owing to drought and heat stress, occur for all scenarios, to a lesser extent in the case of winter cereals.

\section{LITERATURE CITED}

Abrahamsen P, Hansen S (2000) DAISY: an open soil-cropatmosphere system model. Environ Model Softw 15: 313-330

Allen RG, Pereira LS, Raes D, Smith M (1998) Crop evapotranspiration: guidelines for computing crop requirements. Irrigation and Drainage Paper No. 56, FAO, Rome

Baigorria GA, Hansen JW, Ward N, Jones JW, O'Brien JJ (2008) Assessing predictability of cotton yields in the southeastern United States based on regional atmospheric circulation and surface temperatures. J Appl Meteorol Climatol 47:76-91

Belgian Federal Government (2008) Landbouw: statistieken en cijfers. Belgian Federal Government, Brussels, available at http://statbel.fgov.be/nl/statistieken/cijfers/economie/ landbouw/index.jsp (in Dutch)

Bielza M, Costanza G, Catenaro R, Gallego FJ (2008) Regional yield insurance for arable crops in EU-27. Paper presented at the 12th Congress of the European Association of Agricultural Economists, Ghent, Belgium, 26-28 Aug 2008. University Press, Ghent

Blaes X, Defourny P (2003) Retrieving crop parameters based on tandem ERS 1/2 interferometric coherence images. Remote Sens Environ 88:374-385

> Brisson N, Gary C, Justes E, Roche R and others (2003) An overview of the crop model STICS. Eur J Agron 18:309-332

> Challinor AJ, Slingo JM, Wheeler TR, Craufurd PQ, Grimes DIF (2003) Toward a combined seasonal weather and crop productivity forecasting system: determination of the working spatial scale. J Appl Meteorol 42:175-192

Challinor AJ, Wheeler TR, Craufurd PQ, Slingo JM, Grimes DIF (2004) Design and optimisation of a large-area process-based model for annual crops. Agric For Meteorol 124:99-120

> Chmielewski FM, Muller A, Bruns E (2004) Climate changes and trends in phenology of fruit trees and field crops in Germany, 1961-2000. Agric For Meteorol 121:69-78

Christensen JH, Christensen OB (2007) A summary of the PRUDENCE model projections of changes in European climate by the end of this century. Clim Change 81:7-30

Ciais Ph, Reichstein M, Viovy N, Granier A and others (2005) Europe-wide reduction in primary productivity caused by the heat and drought in 2003. Nature 437:529-533

> Drake BG, Gonzalez-Meler MA, Long SP (1997) More efficient plants: a consequence of rising atmospheric $\mathrm{CO}_{2}$ ? Annu Rev Plant Physiol Plant Mol Biol 48:609-639

> Ewert $\mathrm{F}$, Rodriguez D, Jamieson $\mathrm{P}$, Semenov MA and others (2002) Effects of elevated $\mathrm{CO}_{2}$ and drought on wheat: testing crop simulation models for different experimental and climatic conditions. Agric Ecosyst Environ 93:249-266

> Fletcher AL, Sinclair TR, Allen LH Jr (2007) Transpiration responses to vapor pressure deficit in well watered 'slowwilting' and commercial soybean. Environ Exp Bot 61: $145-151$

Holden NM, Brereton AJ, Fealy R, Sweeney J (2003) Possible change in Irish climate and its impact on barley and potato yields. Agric For Meteorol 116:181-196 
Jacob D, Barring L, Christensen OB, Christensen JH and others (2007) An inter-comparison of regional climate models for Europe: model performance in present-day climate. Clim Change 81:31-52

Jaggard KW, Qi A, Semenov MA (2007) The impact of climate change on sugarbeet yield in the UK: 1976-2004. J Agric Sci 145:367-375

Jones JW, Hoogenboom G, Porter $\mathrm{CH}$, Boote $\mathrm{KJ}$ and others (2003) The DSSAT cropping system model. Eur J Agron 18:235-265

Jones PD, Lister DH, Jaggard KW, Pidgeon JD (2003) Future climate impact on the productivity of sugar beet (Beta vulgaris L.) in Europe. Clim Change 58:93-108

Kattge J, Knorr W (2007) Temperature acclimation in a biochemical model of photosynthesis: a reanalysis of data from 36 species. Plant Cell Environ 30:1176-1190

Kimball BA, Kobayashi K, Bindi M (2002) Responses of agricultural crops to free-air $\mathrm{CO}_{2}$ enrichment. Adv Agron 77: 293-368

Kjaergsaard JH, Plauborg F, Mollerup M, Petersen CT, Hansen S (2008) Crop coefficients for winter wheat in a sub-humid climate regime. Agric Water Manage 95:918-924

Lobell DB, Asner GP (2003) Climate and management contributions to recent trends in US agricultural yields. Science 299:1032

Long SP, Ainsworth EA, Leakey ADB, Nosberger J, Ort DR (2006) Food for thought: lower-than-expected crop yield stimulation with rising $\mathrm{CO}_{2}$ concentrations. Science 312: 1918-1921

Meehl GA, Tebaldi C (2004) More intense, more frequent, and longer lasting heat waves in the 21 st century. Science 305:994-997

Menzel A, von Vopelius J, Estrella N, Schleip C, Dose V (2006a) Farmers' annual activities are not tracking the speed of climate change. Clim Res 32:201-207

Menzel A, Sparks TH, Estrella N, Koch E and others (2006b) European phenological response to climate change matches the warming pattern. Glob Change Biol 12:1969-1976

> Mo XG, Liu SX, Lin ZH, Lin ZH, Guo RP (2009) Regional crop yield, water consumption and water use efficiency and their responses to climate change in the North China Plain. Agric Ecosyst Environ 134:67-78

Monsi M, Saeki T (1953) Über den Lichfaktor in den Pflanzengesellschaften und seine Bedeutung für die Stoffproduktion. Jpn J Biotechnol 14:22-52

> Monteith JL, Moss CJ (1977) Climate and the efficiency of crop production in Britain. Philos Trans R Soc B 281:277-294

> Moonen AC, Ercoli L, Mariotti M, Masoni A (2002) Climate change in Italy indicated by agrometeorological indices over 122 years. Agric For Meteorol 111:13-27

Nash JE, Sutcliffe JV (1970) River flow forecasting through conceptual models. I. A discussion of principles. J Hydrol 10:282-290

Nicholls N (1997) Increased Australian wheat yield due to recent climate trends. Nature 387:484-485

Ntegeka V, Boukhris O, Willems P, Baguis P, Roulin E (2008) Climate change impact on hydrological extremes along rivers and urban drainage systems in Belgium. II. Study of rainfall and ETo climate change scenarios. CCI-HYDR project. Report to the Belgian Federal Ministry of Science Policy. Catholic University, Leuven, available at www. kuleuven.be/hydr/cci/reports/CCI-HYDR_II-Climate ChangeScenarios.pdf
Olesen JE, Carter TR, Diaz-Ambrona CH, Fronzek S and others (2007) Uncertainties in projected impacts of climate change on European agriculture and ecosystems based on scenarios from regional climate models. Clim Change 81:123-143

Orlandini S, Nejedlik P, Eitzinger J, Alexandrov V and others (2008) Impacts of climate change and variability on european agriculture results of inventory analysis in COST 734 countries. Trends Dir Clim Res 1146:338-353

Piccinni G, Ko JH, Marek T, Howell T (2009) Determination of growth-stage-specific crop coefficients (K-C) of maize and sorghum. Agric Water Manage 96:1698-1704

> Pidgeon JD, Werker AR, Jaggard KW, Richter GM, Lister DH, Jones PD (2001) Climatic impact on the productivity of sugar beet in Europe, 1961-1995. Agric For Meteorol 109: $27-37$

$>$ Porter JR, Semenov MA (2005) Crop responses to climatic variation. Philos Trans R Soc B 360:2021-2035

> Porter JR, Jamieson PD, Wilson DR (1993) Comparison of the wheat simulation models, AFCWHEAT2, CERES-Wheat and SWHEAT for non-limiting conditions of crop growth. Field Crops Res 33:131-157

> Reidsma P, Ewert F, Lansink AO, Leemans R (2009) Vulnerability and adaptation of European farmers: a multi-level analysis of yield and income responses to climate variability. Reg Environ Change 9:25-40

RMI (Royal Meteorological Institute) (2009) Klimatologisch overzicht van het jaar 2008. Royal Meteorological Institute of Belgium, Brussels, available at www.meteo.be/meteo/ view/nl/2827848-2008.html (in Dutch)

Rodriguez D, Sadras VO (2007) The limit to wheat water use efficiency in eastern Australia. I. Gradients in the radiation environment and atmospheric demand. Aust J Agric Res 58:287-302

Saxton KE, Rawls WJ (2006) Soil water characteristic estimates by texture and organic matter for hydrologic solutions. Soil Sci Soc Am J 70:1569-1578

Semenov MA (2009) Impacts of climate change on wheat in England and Wales. J R Soc Interface 6:343-350

Št'astná M, Toman F, Dufkova J (2010) Usage of SUBSTOR model in potato yield prediction. Agric Water Manag 97: $286-290$

Stockle CO, Donatelli M, Nelson RL (2003) CropSyst, a cropping systems simulation model. Eur J Agron 18:289-307

Trnka M, Hlavinka P, Semeradova D, Dubrovsky M, Zalud Z, Mozny M (2007) Agricultural drought and spring barley yields in the Czech Republic. Plant Soil Environ 53:306-316

Tao F, Hayashi Y, Zhang Z, Sakamoto T, Yokozawa M (2008) Global warming, rice production, and water use in China: developing a probabilistic assessment. Agric For Meteorol 148:94-110

Trnka M, Eitzinger J, Hlavinka P, Dubrovsky $M$ and others (2009) Climate-driven changes of production regions in central Europe. Plant Soil Environ 55:257-266

Vanclooster M, Viaene P, Diels J, Feyen J (1995) A deterministic validation procedure applied to the integrated soil crop model WAVE. Ecol Modell 81:183-195

Wheeler TR, Craufurd PQ, Ellis RH, Porter JR, Prasad PVV (2000) Temperature variability and the yield of annual crops. Agric Ecosyst Environ 82:159-167

Williams JR, Jones CA, Kiniry JR, Spanel DA (1989) The EPIC crop growth model. Trans ASAE 32:497-511

Willmott CJ (1981) On the validation of models. Phys Geogr 2: $184-194$

Proofs received from author(s): September 27, 2010 